\title{
Projetos de Educação Ambiental de escolas públicas e particulares do Distrito Federal: uma análise comparativa
}

\author{
Milca Vieira de Barros Neta ${ }^{1}$ \\ Bárbara Medeiros Fonseca ${ }^{2}$
}

Resumo: Este trabalho teve como objetivo comparar projetos de Educação Ambiental (EA) desenvolvidos em escolas públicas (PU) e particulares (PA) do Distrito Federal (DF), Brasil, quanto às seguintes características: temáticas, metodologias empregadas, grau de interesse dos participantes, envolvimento dos diferentes componentes da comunidade escolar e parcerias. O estudo foi realizado no primeiro semestre de 2009. Foram contatadas 80 PU e 30 PA, das quais dez e oito, respectivamente, apresentavam projetos de EA já concluídos ou em desenvolvimento há pelo menos um ano. Dessas, foram realizadas entrevistas estruturadas em cinco PU e três PA. Em geral, os projetos foram semelhantes quanto às atividades desenvolvidas. Entre as instituições entrevistadas, as PU se apresentaram melhores do que as PA em relação ao número de pessoas envolvidas e ao índice de participação e interesse, mostrando maior preocupação com as questões ambientais.

Palavras-chave: Comunidade escolar. Instituições de ensino. Educação Ambiental.

\section{Environmental Education projects of public and private schools in the Federal District: a comparative analysis}

Abstract: This study aimed at comparing Environmental Educational (EE) projects developed in public (PU) and private (PR) schools in the Federal District (FD), Brazil, considering the following characteristics: themes, methods used, degree of interest of participants, participation of the school community and partnerships. The study took place during the first half of 2009. Altogether 80 PU and 30 PR were contacted, among which ten and eight, respectively, presented EE projects already finished or under development for at least one year. Structured interviews were then conducted in five of those ten PU and in three of those eight PA. In general, projects were similar with regard to activities. Among the

\footnotetext{
${ }^{1}$ Mestranda em Planejamento e Gestão Ambiental pela Universidade Católica de Brasília(UCB), Asa Norte, Brasil, milcaneta@gmail.com

${ }^{2}$ Doutora em Ecologia, Docente do Curso de Biologia da Universidade Católica de Brasília(UCB), Taguatinga, Brasil,bm_fonseca@yahoo.com.br
} 
institutions surveyed, the PU were better then the PA in relation to the number of people involved and the level of participation and interest, showing a greater concern with environmental issues.

Keywords: School community. Education institutions. Environmental Education.

\section{Proyectos de Educación Ambiental de escuelas públicas y particulares del Distrito Federal: un análisis comparativo}

Resumen: Este trabajo tuvo como objetivo comparar proyectos de Educación Ambiental (EA) desenvolvidos en escuelas públicas (PU) y particulares (PA) del Distrito Federal (DF), Brasil, en cuanto a las siguientes características: temáticas, metodologías empleadas, grado de interés de los participantes, envolvimiento de los diferentes componentes de la comunidad escolar y colaboradores. El estudio se realizó el primer semestre de 2009. Se contactaron 80 PU y 30 PA, de las cuales dieciocho, respectivamente, presentaban proyectos de EA ya concluídos o en desarrollo desde hace por lo menos un año. De estas, se realizaron entrevistas estructuradas en cinco PU y tres PA. En general, los proyectos fueron semejantes en lo referente a las actividades desarrolladas. Entre las instituciones entrevistadas, las PU se presentaron mejores que las PA con relación al número de personas envolvidas y al índice de participación e interés, mostrando mayor preocupación con las cuestiones ambientales.

Palabras clave: Comunidad escolar. Instituciones de enseñanza. Educación Ambiental.

\section{Introdução}

Alguns estudos realizados em âmbito nacional têm apontado uma boa inserção da Educação Ambiental (EA) nas escolas brasileiras. Segundo Veiga, Amorim e Blanco Cossío (2005), 94\% das escolas de ensino fundamental brasileiras declararam trabalhar com a temática ambiental em seus currículos, o que, segundo os autores, indica quase uma universalização de tal prática.

O Distrito Federal (DF) dispõe atualmente de 620 escolas públicas e 170 escolas particulares, de acordo com dados da Secretaria de Educação (http://www.se.df.gov.br) e do Sindicato dos Estabelecimentos Particulares de Ensino (http://www.sinepe-df.org). Estudos voltados à análise da Educação Ambiental nas escolas do DF restringem-se aos trabalhos de Bizerril e Faria 
(2001, 2003). Estes, no entanto, basearam-se em entrevistas com os professores na intenção de investigar seu conhecimento e percepção ambiental quanto ao Bioma Cerrado, não tendo o objetivo de analisar os projetos de Educação Ambiental em si.

De acordo com Bizerril e Faria (2001), poucos são os professores que consideram seus alunos capacitados e conscientes no que diz respeito aos temas voltados para o meio ambiente. Muitos acreditam que a maioria dos estudantes não apresenta interesse sobre o assunto. Isso dificulta a proposição de opiniões, pois os alunos não conseguem relacionar o que observam no dia a dia com o que encontram no livro didático ou o que ouvem na imprensa. Nesse mesmo trabalho foram apontadas algumas diferenças entre escolas públicas e particulares. As primeiras dispõem de menos recursos para projetos de EA e professores pouco motivados quando comparadas às segundas. A falta de domínio de conteúdo e a baixa remuneração do profissional contribuem para esse quadro, que parece se repetir em outras regiões brasileiras (IZUWA; AUGUSTO; ROMBALDI, 1997; MEDINA, 1994).

Bizerril e Faria (2003) investigaram o enfoque do tema "Cerrado" nas escolas do DF. Segundo eles, a maioria dos professores entrevistados $(87,8 \%)$ acredita que problemas ligados à pobreza e aos serviços urbanos são mais importantes do que problemas ligados à educação e ao meio ambiente. A diversidade dos problemas vivenciados pelas escolas, tanto pelas especificidades de seu corpo docente e discente quanto pela sua localização física e social, evidencia a necessidade de se proporem métodos de trabalho que possibilitem considerar as peculiaridades a que as situações em torno dos problemas ambientais estão relacionadas (MELO, 2001).

Outro problema mencionado é a carência de divulgação científica em linguagem adequada nas escolas, bem como o baixo interesse dos docentes por tais informações. Costa (1998), em estudo realizado em cinco países, incluindo o Brasil, observou que os professores consideram a difusão científica importante, mas afirmaram não se envolverem em atividades desse tipo por falta de tempo ou por não terem treinamento adequado. Nesse sentido, porém, vale destacar iniciativas como o projeto "Água como matriz ecopedagógica", desenvolvido pela Universidade de Brasília em parceria com a Secretaria de Estado da Educação do Distrito Federal em escolas e comunidades ribeirinhas do DF, o qual tem entre seus objetivos a formação de professores e a elaboração de materiais didáticos sobre o tema "Água e Cerrado" (CATALÃO; RODRIGUES, 2006), além de publicações como as de Dias (2006, 2010), com várias sugestões de atividades práticas de EA.

As dificuldades enfrentadas pelas escolas no desenvolvimento da temática ambiental acabam influenciando negativamente a formação de indivíduos aptos para a construção de sociedades sustentáveis, uma vez que o educador ambiental 
tem um papel fundamental para facilitar essa sensibilização dentro das escolas e nas comunidades ao seu redor.

Diante disso, teve-se como objetivo analisar o cenário atual dos projetos de EA realizados em escolas públicas e privadas do DF. Este estudo encontra-se registrado no Conselho de Ética (CEP/UCB) sob o número 044/2009.

\section{Material e métodos}

Durante o primeiro semestre de 2009, foi realizada uma consulta por telefone em 80 escolas públicas e 30 escolas particulares, em diferentes regiões administrativas do DF, sobre a existência de projetos de EA já concluídos ou em desenvolvimento há pelo menos um ano em cada instituição.

Nas escolas que atendiam a esse critério, foram agendadas entrevistas utilizando-se quatro formulários adaptados de Dusi (2006). As entrevistas foram aplicadas a no máximo duas pessoas indicadas pela própria escola, em geral idealizadores ou responsáveis diretos pelos projetos de EA. Os tópicos abordados em cada formulário foram: a) identificação e caracterização da escola (Formulário 1); b) metodologias empregadas nos projetos (Formulário 2); c) dados qualitativos sobre aspectos das metodologias e práticas pedagógicas nos projetos de EA (Formulário 3); d) dados quantitativos sobre a participação dos beneficiados e/ou envolvidos nos projetos ou programas de EA (Formulário 4).

\section{Resultados}

Entre as escolas contatadas, apenas 10 públicas e cinco particulares relataram apresentar projetos de Educação Ambiental concluídos ou em desenvolvimento há pelo menos um ano. Destas, foram efetivamente analisadas no presente estudo oito instituições, sendo cinco públicas (identificadas como PU1, PU2, PU3, PU4, PU5) e três privadas (identificadas como PA1, PA2 e PA3). A Tabela 1 apresenta uma caracterização geral das escolas.

\section{Características e metodologias dos projetos}

\section{Escolas Particulares}

As três escolas particulares entrevistadas apresentaram projetos bastante distintos entre si com relação às metodologias empregadas, à participação direta das pessoas e à forma como são desenvolvidos.

$\mathrm{Na}$ escola PA1, o entrevistado foi um funcionário do setor de serviços gerais. O projeto é baseado em coleta seletiva de todo o lixo produzido pela escola, o qual é vendido para cooperativas. Ocorre desde 2001, embora venha 
sendo apresentado aos alunos somente desde 2006. Não possui previsão de término e não está inserido no Projeto Político-Pedagógico da escola. De acordo com o entrevistado, no projeto da PA1 falta colaboração tanto da parte de alunos quanto de professores, o que gera poucos resultados. O projeto é desenvolvido por meio de palestras em sala de aula, buscando atrair a participação dos alunos. Entretanto, os verdadeiros envolvidos na ideia são os dezoito funcionários da limpeza e alguns alunos do grêmio estudantil, além de alguns poucos estudantes voluntários. Ou seja, a participação dos alunos em geral, dos pais e dos professores é quase nula.

O entrevistado da escola PA2 foi um professor da escola. O projeto foi iniciado em 2008 e enquadra-se no âmbito formal, estando incluído no Projeto Político-Pedagógico da instituição. Tem como objetivo anular o prejuízo ambiental provocado pelo consumo de energia e combustível e pela produção de lixo da escola, ou seja, capturar a quantidade de $\mathrm{CO}_{2}$ que a mesma emite, a partir da avaliação de sua taxa de emissão e da quantidade de árvores necessárias para compensar esse prejuízo ambiental. O trabalho se dá por meio do plantio de mudas, que são manuseadas e mantidas pelos alunos em uma estufa na própria instituição. Ao contrário da escola PA1, há participação de toda a comunidade escolar, inclusive dos pais. O envolvimento dos professores é eficaz e ocorre de forma interdisciplinar. O projeto se desenvolve por meio de aulas práticas e oficinas, com coletas de sementes, plantio e manutenção das mudas. Além disso, há saídas de campo e visitas técnicas para se conhecerem outros lugares que tenham ligação com as ideias do projeto.

O projeto da escola PA3 começou em 2006, sem previsão de término, de acordo com o professor entrevistado. Assim como na escola PA1, não consta no Projeto Político-Pedagógico da escola, sendo considerado de âmbito não formal. Baseia-se em uma ecovila, que dispõe de diferentes recursos educativos voltados para uma relação harmônica com o meio ambiente, como aquecedor solar de baixo custo, biofertilizante, viveiro de plantas medicinais e uma sala de aula construída com superadobe. O projeto da escola traz como objetivos principais conscientizar sobre a importância da utilização sustentável dos recursos naturais e energéticos e produzir e reproduzir tecnologias sustentáveis permanentes. Os resultados obtidos são apresentados pelos participantes do projeto na Feira do Conhecimento, que ocorre uma vez ao ano e envolve todos os professores e alunos. O projeto se desenvolve por meio de cursos ministrados por professores, exposições em feiras comunitárias, oficinas e visitas a lugares afins.

\section{Escolas Públicas}

As cinco escolas públicas analisadas possuem características bem parecidas em alguns aspectos, como o tempo de duração dos projetos. Em três delas - 
PU1, PU3 e PU5 - os projetos existem desde 2007, sem tempo determinado para acabar. Os projetos mais antigos são os das escolas PU2, que ocorre desde 2006, com duração prevista para quatro anos, e PU4, que ocorre há mais de oito anos. Outro ponto em comum entre elas é a origem dos recursos para a instalação e manutenção dos projetos. Nas cinco instituições os recursos vêm da própria escola, dos professores e da APM (Associação de Pais e Mestres). As escolas PU1 e PU5 contam ainda com o apoio de parceiros e, no caso da escola PU5, os recursos vêm também do Estado. Todos os cinco projetos estão documentados e inseridos no Projeto Político-Pedagógico das escolas, sendo considerados de âmbito formal.

De modo geral, os projetos contam com a participação de todos os alunos. Em alguns casos, há também envolvimento dos pais (PU4 e PU5), além de voluntários e monitores (PU4, PU5, PU1 e PU2). No que diz respeito à forma como ocorrem os projetos, todos são baseados em aulas teóricas e práticas. A participação dos professores se dá em determinadas disciplinas, como Ciências/Biologia, Artes, Matemática, Português, Química e, no caso da escola PU1, PD (Parte Diversificada). Apenas as escolas PU4 e PU5 contam com a integração de todos os professores.

A escola PU1 possui sua própria Agenda 21, na qual há um projeto que visa à cidadania e ao meio ambiente. Inseridos nele, existem subprojetos desenvolvidos por meio de horta, viveiro, agrofloresta e, principalmente, reciclagem. Tem como principal objetivo a conscientização da comunidade escolar e local no que diz respeito à necessidade da reciclagem. É um projeto que gera lucros para a própria escola e que conta com o apoio dos alunos, que trazem materiais recicláveis de casa. De acordo com o professor entrevistado, antes do trabalho havia muita sujeira e pichação na escola, além de problemas com drogas e focos de dengue. A implantação da Agenda 21 local encontrou resistência por parte dos alunos e também dos professores, mas, segundo ele, após o início do projeto houve um aumento na conscientização quanto à necessidade da coleta seletiva e da reciclagem dos resíduos produzidos na escola e uma redução considerável no consumo de energia e água. É apresentado em exposições na Feira de Ciências da cidade, que ocorre uma vez ao ano e na qual são levadas para a comunidade local as ideias e resultados do projeto, além de passeios cívicos e seminários direcionados aos alunos.

Os entrevistados da escola PU2 foram dois professores e, segundo eles, o projeto tem como principal objetivo promover a conscientização dos alunos quanto à necessidade da conservação do Cerrado. Ocorre através de apresentações de programas ambientais e oficinas em que os próprios alunos confeccionam os materiais utilizados no projeto. São ministradas aulas em uma sala feita com material reutilizado, onde se trabalha a teoria juntamente com a prática. São discutidos conceitos e ações por meio de horta, estufa, plantação de 
mudas, compostagem e reutilização de material. Antes do projeto, atitudes ecológicas e práticas agropecuárias eram ministradas superficialmente em algumas disciplinas. Não houve grandes dificuldades para a instalação do projeto, pois já havia boa conscientização, oriunda das aulas que abordavam indiretamente o tema. Após a ação de EA, ocorreu uma economia visível de água e energia na escola e a produção da horta passou a ser utilizada no almoço dos alunos da escola integral. De acordo com os entrevistados, a aceitação dos alunos é muito boa. Eventualmente são feitas visitas técnicas a lugares como a Fazenda Água Limpa, pertencente à Universidade de Brasília. De acordo com um dos professores responsáveis pelo projeto, é possível que se crie um jornal de EA, feito por um estudante de Jornalismo, para ser distribuído em toda a escola.

A escola PU3 oferece recursos parecidos aos das demais, como horta, viveiro e reciclagem. No entanto, destaca-se pelo reaproveitamento de materiais. Sob a supervisão de um professor de Português - o entrevistado -, que se diz "apaixonado pelo meio ambiente", ocorre a confecção de vassouras e pufes de garrafas PET e a construção de mesas e jogos educativos a partir de latas e carteiras quebradas. Os objetivos do projeto são promover a sensibilização para os problemas ambientais, em especial para as mudanças climáticas, e despertar o interesse pelo reaproveitamento, por um consumo consciente e pela conservação e melhoria do ambiente escolar. Antes do projeto, a preocupação com a degradação ambiental era praticamente inexistente na escola PU3. A ideia do projeto foi bem aceita por alunos e professores. A quebra da rotina de sala de aula aumentou visivelmente a empolgação dos alunos. Diante disso, de acordo com o professor, os resultados são bastante positivos, atingindo as expectativas, principalmente quando se percebem alunos mais preocupados com o ambiente escolar. O projeto já fez exposições em feiras culturais realizadas na própria instituição. As oficinas são frequentes, sendo desenvolvidas por professores e abertas a todos os alunos. Para visualizar melhor o que aprendem na teoria, os alunos já fizeram visitas a parques, Áreas de Proteção Permanente e a uma usina de tratamento de lixo.

O projeto da escola PU4 é o mais antigo entre todas as escolas públicas analisadas, ocorrendo há mais de oito anos. De acordo com o professor entrevistado, intitula-se "Um meio muito especial". Conta com horta, minhocário, compostagem, estufa, plantas medicinais, pomar e tem como foco a reciclagem. É mantido com recursos oriundos do próprio projeto, por meio da venda de materiais recicláveis, verduras e legumes da horta, e mudas de plantas. Conta com a participação de alunos com deficiências auditiva, múltipla, visual, física e cadeirantes, visando também ao seu desenvolvimento psicomotor por meio da relação com o meio ambiente. O projeto apresentou algumas resistências no início, mas, segundo o representante da escola, vem surtindo resultados positivos. São oferecidos cursos a professores de outras instituições, além de 
feiras comunitárias, em que são vendidas as mudas e o material da horta, e visitas técnicas com os alunos a parques e cooperativas. O projeto promove também passeatas na comunidade próxima à escola, trabalhando a conscientização das pessoas e fazendo a coleta de material nas residências.

A professora entrevistada da escola PU5 foi uma das mais radiantes, ficando orgulhosa de falar que a escola é chamada pelos professores e funcionários de "lugar de gente feliz". Os ideais do seu projeto são baseados nos Sete Saberes para a Educação do Futuro, desenvolvidos pelo sociólogo e filósofo francês Edgar Morin (2000). É formado por sete subprojetos, relacionados à gestão do lixo, da alimentação saudável e da cidadania, com a preocupação na formação de crianças e jovens conscientes sobre o seu papel no meio em que vivem. Seus objetivos são transformar "os sete saberes necessários à educação do futuro" em prática pedagógica como eixo condutor de diversas aprendizagens a serem construídas, impulsionando a mudança paradigmática na educação, envolver educadores e educandos no processo de construção do sujeito ecológico, melhorar a limpeza da escola, aproveitar o lixo para transformá-lo em utilidade e contribuir para a construção do cidadão brasileiro por meio do respeito às leis. Segundo a entrevistada, antes do projeto havia um individualismo muito grande, falta de engajamento nas questões ambientais e problemas com o lixo, pois não havia a coleta seletiva. O processo de implantação do projeto foi gradativo, sem resistência da comunidade escolar. Os bons resultados iniciais em sala de aula levaram à ampliação do projeto para toda a escola. Os resultados obtidos após a ação de EA foram o fortalecimento do coletivo (professores, pais e alunos), engajamento das pessoas sobre as questões ambientais, aumento visível na limpeza da escola, bem como diminuição do desperdício e da violência entre alunos. O projeto se desenvolve por meio de cursos de EA para os próprios professores da instituição, além de feiras, oficinas e visitas a lugares de interesse do projeto.

\section{Aspectos das metodologias e práticas pedagógicas nos programas ou projetos em EA - dados qualitativos}

Neste tópico, os entrevistados foram questionados se seu respectivo programa ou projeto "atingiu" ou "não atingiu" os seguintes aspectos: A) considerou danos causados aos sistemas naturais; B) apresentou um aumento do interesse dos envolvidos pelo tema; C) apresentou ações que possibilitam a verificação de substituição de hábitos; D) promoveu mudanças no estilo de vida dos envolvidos por meio de relatos ou novas ações apresentadas; E) promoveu o interesse de pessoas ou instituições em conhecer o andamento e o resultado do(s) programa(s) implantado(s); F) possibilitou a verificação de seus indicadores de avaliação e acompanhamento. Segundo os entrevistados, de modo geral todos os 
aspectos puderam ser classificados como "atingidos". Sobre a verificação dos indicadores de avaliação dos programas ou projetos, porém, a escola PU3 afirmou ser possível tal controle, mas não é feito. Na escola PA1, todos os aspectos citados foram classificados como "atingidos", mas somente entre os funcionários da instituição, excluindo alunos e demais membros da comunidade escolar.

\section{Participação dos beneficiados e/ou envolvidos nos projetos ou programas de EA - dados quantitativos}

\section{A - Pessoas envolvidas diretamente nos programas educacionais}

Das três escolas particulares, apenas PA2 conta com a participação efetiva de toda a escola. O contrário ocorre nas cinco escolas públicas, entre as quais apenas a escola PU3 apresenta uma participação de apenas parte da comunidade escolar (Figura 1).

\section{B - Multiplicadores capacitados na metodologia proposta pelos programas de EA implantados}

Neste item foram levadas em consideração as pessoas treinadas com os conhecimentos necessários para se difundir a ideia do projeto. Diante disso, foram classificados como "parcialmente formados" aqueles participantes que, embora diretamente ligados aos projetos, não apresentam conhecimento total dos conteúdos intrínsecos e como "formado integralmente" os participantes diretos de cada projeto que apresentam total domínio das informações associadas aos conteúdos intrínsecos. Tanto nas escolas particulares como nas públicas o número de formados integralmente foi baixo (PA2 - 1,2\%; PA3 - 20\%; PU1 0,2\%; PU2 - 0,2\%; PU3 - 1\% e PU4 - 0,7\%), com exceção das escolas PA1 e PU5, onde, de acordo com os responsáveis pelos projetos, cerca de $45 \%$ e $70 \%$ da comunidade escolar, respectivamente, tem conhecimento e domínio sobre os ideais do projeto do qual faz parte.

\section{C - Atividades comunitárias realizadas ao longo do desenvolvimento dos projetos}

Entre as escolas particulares, apenas PA2 apresentou atividades comunitárias, como unir a comunidade escolar e pais e alunos na plantação das mudas, por exemplo. A tendência foi inversa entre as escolas públicas, que chegaram a apresentar até 10 atividades (PU4), com exceção de PU2, sem nenhuma (Tabela 2). 


\section{D - Parceiros envolvidos no início do projeto e parceiros atuais}

O número de parceiros (empresas, outras instituições de ensino, ONGs, administrações regionais) de algumas das escolas analisadas era alto no início devido à construção da estrutura dos projetos. Após sua implementação, a necessidade da maioria das parcerias deixava de existir. Isso ocorreu com as escolas PA3, PU2 e PU4. No entanto, alguns projetos, como os das escolas PA1 e PU3, não contaram com nenhuma parceria. Já as escolas PA2 e PU5 vêm mantendo o mesmo número de parceiros do início dos projetos. Somente a escola PU1 apresentou um aumento no número de parceiros (Figura 2).

\section{Discussão}

A dificuldade de encontrar escolas que apresentassem projetos de EA concluídos recentemente ou em andamento revela a carência de iniciativas relacionadas a esse tema no universo de instituições de ensino do DF. Casagrande (2007) atribuiu o problema de organização e gestão das escolas públicas brasileiras à total falta de diálogo e consenso entre governo e professores. Isso talvez explique a falta de iniciativas no DF como um todo.

Independentemente das razões do atraso ou dificuldade para implementar ações voltadas para o meio ambiente, é preciso aperfeiçoar as práticas educacionais, tornando a Educação Ambiental uma prática fundamental nas escolas. Assim como já discutido por Melo (2001), considera-se urgente a necessidade de inserção de uma dimensão ambiental na educação brasileira, tanto na esfera do pensamento, da racionalidade, da sensibilização e das orientações curriculares quanto no nível concreto de trabalho pedagógico em todo o sistema de ensino - da escola básica à universidade.

Sato (2001) apontou como principal barreira ao sucesso de projetos em EA a ilusão de que é uma área fácil de ser estudada ou concretizada. Com isso, a EA fica resumida a ações pontuais que utilizam basicamente o terceiro $R$ (reciclagem), sem posturas críticas sobre o elevado consumismo presente nas sociedades atuais, marcadas por uma relação em que o ser humano exerce domínio sobre a natureza. A autora critica o termo "conscientizar" porque, segundo ela, consciência não é algo que se pode simplesmente dar a alguém. Fazse necessária também a incorporação de práticas pedagógicas transformadoras, sem as quais a dimensão ambiental não é percebida de forma adequada. Em outra questão levantada por essa autora, chamada de (des)envolvimento humano, propõe-se a substituição do termo "desenvolvimento" por "envolvimento", englobando a ética e a solidariedade como pontos primordiais. Nesse sentido, conforme colocado por Pessoa e Braga (2010), espera-se que a EA no âmbito 
escolar inspire mudanças profundas nos modelos de desenvolvimento, influenciando diretamente os hábitos e comportamentos dos indivíduos e resultando na busca de soluções coletivas para os problemas ambientais.

Bizerril e Faria (2001) listaram as várias dificuldades para a inserção da EA nas escolas em geral, entre as quais as relações interpessoais e a capacitação dos professores. Interdisciplinaridade e alto número de sujeitos envolvidos podem ser considerados os principais indicadores de um projeto de EA de sucesso. Segundo Leff (2000), a interdisciplinaridade associada às questões ambientais surgiu em meados da década de 1970, devido à degradação do meio ambiente e ao caráter fragmentado do conhecimento. Para o autor, interdisciplinaridade pode significar uma interconexão de vários campos do conhecimento. Coimbra (2000) conceitua a interdisciplinaridade como um vínculo de um saber com outro saber. O envolvimento dos professores e da coordenação das escolas em um interesse mútuo é apontado por Bizerril e Faria (2001) como um ponto-chave para o bom andamento de um projeto de EA.

Vários autores já discutiram os problemas decorrentes da transmissão de conhecimentos fragmentada, por meio de disciplinas isoladas (e.g., MELO, 2001; PESSOA; BRAGA, 2010; TRAVASSOS, 2001). No presente estudo, observouse que alguns professores ainda veem a EA como um tema exclusivo de disciplinas como Ciências e Biologia. Como consequência, a abordagem de temas ligados ao meio ambiente acaba ficando a cargo de professores dessas áreas. Vale dizer, porém, que a Política Nacional de Educação Ambiental (BRASIL, 1999) já exige a abordagem interdisciplinar da EA, deixando claro que esta deve ocorrer de forma dinâmica em todos os níveis e modalidades do processo educativo. Ainda assim, alguns autores reconhecem a existência de empecilhos tanto teóricos quanto práticos, os quais dificultam tal processo nos trabalhos pedagógicos de EA (PESSOA; BRAGA, 2010). Uma das escolas entrevistadas no presente estudo (PU2), por exemplo, possui uma disciplina exclusiva de EA. Após as grandes conquistas alcançadas pela EA ao longo dos anos, pensar em reduzir tudo o que se pode aprender através dela a uma única disciplina seria uma forma de regredir ao pensamento de que EA é uma área isolada dos demais conhecimentos. A EA vista de forma interdisciplinar favorece o aprendizado através de pontes sem fronteiras, que nos permitem compreender o meio ambiente exatamente como ele deve ser - abrangendo os campos ambientais, sociais, éticos, culturais, políticos, econômicos, entre outros.

Outro aspecto importante a ser discutido aqui é a forma como a EA vem sendo conduzida nas escolas estudadas. Para Echeverría, Rodrigues e Silva (2009), a complexidade dos problemas ambientais tem gerado conflitos que dificultam a eficiência da EA. No âmbito das escolas é preciso que fique definido como objetivo pedagógico se a EA será de fato aplicada, ou seja, definir se a mudança será nas atitudes, por conta da visão de meio ambiente como natureza, 
internalizando a necessidade de envolvimento do ser humano. Isso é de grande importância para evitar o que, segundo Dias (2003), é bastante comum: a confusão feita entre Ecologia e Educação Ambiental. De forma muitas vezes ingênua, as aulas resumem-se à abordagem de temas como desmatamento, efeito estufa, camada de ozônio e coleta de latinhas de alumínio. No presente estudo, os projetos, em sua maioria, basearam-se em atividades como coleta seletiva, cultivo de hortas e reciclagem. Uma das escolas particulares entrevistadas explora também o conceito de ecovila, que consiste na adoção de um modelo de ocupação do território que rompe com os paradigmas de uso da terra (JORGE, 2008). Ressalta-se que a EA representa, principalmente, uma mudança de hábitos e pensamentos, priorizando o meio ambiente. De acordo com a lei que institui a Política Nacional de Meio Ambiente (BRASIL, 1981), o mesmo é definido como "o conjunto de condições, leis, influências e interações que regem a vida, em todas as suas formas", ou seja, são todos os fatores que agem diretamente na formação do indivíduo e se relacionam com o meio ambiente.

Passando agora ao grau de participação nos projetos de EA, entre as escolas analisadas as públicas apresentaram maior interação dos envolvidos quando comparadas às particulares, principalmente no que diz respeito aos alunos. Quanto ao corpo docente, apenas três escolas (PA2, PU4 e PU5) informaram ter todos os seus professores participando de seus projetos. De acordo com Souza (2007), embora ocorra uma constante convivência entre coordenação, professores e alunos, não acontece um diálogo essencial para desenvolver projetos de interesse de todos. De modo geral, a resistência dos professores ao envolvimento em projetos ambientais foi visível neste estudo, ficando a responsabilidade dos projetos nas mãos de poucos. Para se mudar essa realidade, Gadotti (2000) enfatiza a necessidade de formação de um novo professor, que seja um aprendiz permanente e mediador de um novo conhecimento. Para Santos, Tagliani e Vieira (2010), os professores não podem ser apenas agentes de transmissão de informações, devem preparar o aluno para ser um agente no seu aprendizado.

Para Martins (2005), a Educação Ambiental deve ser um processo envolvente, que agregue todos os funcionários da escola, pais, representantes e membros da comunidade à qual a escola serve. O presente estudo apontou uma diferença clara nesse aspecto comparando as escolas públicas e particulares entrevistadas. Através das respostas obtidas com os entrevistados, que colocaram em números as participações nos projetos, entre as escolas particulares apenas a PA2 conta com um projeto com $100 \%$ de apoio e envolvimento de todos os membros da comunidade escolar. Já nas escolas públicas a tendência foi inversa: apenas o projeto de uma instituição (PU3) não apresentou a participação de todos os alunos da escola. Ainda assim, é uma participação de aproximadamente $27 \%$ de toda a comunidade escolar. 
Nas escolas analisadas, entre todos os que participaram de alguma forma dos projetos, o número de multiplicadores capacitados, ou seja, com total segurança e conhecimento acerca dos objetivos do projeto, foi relativamente baixo. As escolas públicas, porém, se sobressaíram por maior envolvimento de pessoas interessadas. Em razão disso, a possibilidade de se expandirem as ideias abordadas nos projetos parece ser maior nas escolas públicas.

Segundo Nieto Caraveo (2001), dependendo dos propósitos e do público, a EA terá metodologias, materiais e temáticas bastante distintos entre si. De acordo com Bizerril e Faria (2003), no que diz respeito a técnicas empregadas para a EA, não existe diferença significativa entre ensino público e privado no Distrito Federal. Entretanto, nas escolas privadas haveria maior tendência à diversificação, em função, especialmente, dos maiores recursos que as mesmas possuem. O presente trabalho, porém, de modo geral não encontrou diferenças no que se refere à diversificação de atividades propostas nos projetos ambientais das escolas públicas e particulares, embora algumas instituições tenham apresentado recursos didáticos mais específicos, como aquecedor solar de baixo custo e sala de aula de superadobe na PU3, ou projetos ambientais associados ao desenvolvimento da cidadania (PU1 e PU5).

Vale, porém, a afirmação de Bizerril e Faria (2003) sobre a diferença quanto à disponibilidade de recursos financeiros entre escolas públicas e particulares. De acordo com os entrevistados das escolas públicas, seus projetos se sustentam com certa dificuldade, muitas vezes financiados com recursos dos próprios professores.

As parcerias são de grande importância no andamento de projetos ambientais, pois se tornam uma força a mais para mantê-los. No quadro de análise das oito instituições, ainda se tem uma carência desse tipo de força, uma vez que apenas uma escola (PU1) obteve aumento no número de parceiros ao longo do desenvolvimento do projeto. Na maioria das escolas (PA1, PA3, PU2, PU3 e PU4), o apoio de parceiros em seus projetos foi reduzido ou nunca existiu. Talvez isso não seja um aspecto essencial ao sucesso de um projeto, mas, sem dúvida, favorece o alcance dos seus objetivos.

Diante desse contexto, elaborou-se um organograma com aspectos considerados relevantes, em maior ou menor grau, para o sucesso de um projeto de EA (Figura 3). Segundo Vargas (2005), para que ocorram as grandes transformações da sociedade, não são necessários apenas decretos e leis, é preciso sensibilização/conscientização e vontade política para a mudança, ou seja, a união de esforços, sonhos e esperanças em torno de um projeto de interesse comum, visando à dignidade e qualidade de vida da população. Dessa forma, o que realmente define se um projeto ambiental está sendo capaz de cumprir seu papel na rotina diária de seus envolvidos e, consequentemente, na diminuição dos impactos ao meio ambiente é se ele está causando sensibilização e, como prova 
disso, uma mudança nos hábitos de vida das pessoas que dele participam direta ou indiretamente.

Foi verificado que, a princípio, tanto as escolas públicas quanto as particulares apresentaram em seus projetos todas as ferramentas necessárias à obtenção de um projeto ambiental de sucesso. Vale ressaltar, porém, que o quadro descrito no presente estudo baseou-se na perspectiva dos responsáveis pelos projetos. Aponta-se como ideia para um estudo futuro a investigação da opinião do público participante, particularmente dos alunos.

Segundo Narcizo (2009), projetos realizados e gerenciados por pequenos grupos, muitas vezes de forma isolada, apresentam pouco sucesso na transformação dos indivíduos envolvidos. Nesse sentido, de modo geral, os projetos analisados no presente estudo podem ter dificuldades em levar a mudanças da atitude num alcance mais amplo, fora do ambiente escolar.

Por fim, os resultados apresentados apontam que o DF parece estar longe de se inserir no que Veiga, Amorim e Blanco Cossío (2005) consideraram como uma quase totalidade de escolas brasileiras que enquadram a temática ambiental em seus currículos. Apesar da quantidade relativamente pequena de projetos de EA nas escolas do DF, houve uma tendência a favor das escolas públicas em relação ao número de pessoas envolvidas e ao índice de participação e interesse. Tal fato sugere que, apesar das dificuldades inerentes ao ensino público no Brasil, as escolas públicas do DF, em geral, parecem estar mais atentas às questões ambientais quando comparadas às particulares.

\section{Agradecimentos}

As autoras agradecem à Profa. Dra. Maria do Socorro Rodrigues Ibañez (UnB) e aos revisores anônimos pelas valiosas sugestões para o aprimoramento deste trabalho.

\section{Referências}

BIZERRIL, Marcelo Ximenes Aguiar; FARIA, Dóris S. Percepção de professores sobre a educação ambiental no ensino fundamental. Revista Brasileira de Estudos Pedagógicos. Brasília, v. 82 , n. 200/201/202, p. 57-69, jan./dez. 2001.

BIZERRIL, Marcelo Ximenes Aguiar; FARIA, Dóris S. A escola e a conservação do cerrado: uma análise do ensino fundamental do Distrito Federal. Revista Eletrônica do Mestrado de Educaşão Ambiental, Rio Grande, v. 10, p. 19-31, jan./jun. 2003.

BRASIL. Lei no 6.938, de 31 de agosto de 1981. Institui a Política Nacional de Meio Ambiente. Diário Oficial da República Federativa do Brasil, Brasília, DF, 2 set. 1981. 
. Lei n ${ }^{\circ} 9.795$, de 27 de abril de 1999. Dispõe sobre a educação ambiental, institui a Política Nacional de Educação Ambiental e dá outras providências. Diário Oficial da República Federativa do Brasil, Brasília, DF, 28 abr. 1999.

CASAGRANDE, Renato José. Pesquisa avalia percepções da educação pública. Linha direta: educação por escrito, ano 10, p. 32-35, fev. 2007.

CATAlÃo, Vera Lessa; RODRIGUES, Maria do Socorro (Org.). Água como Matriz Ecopedagógica. Brasília: Edição das autoras, 2006.

COIMBRA, José de Ávila Aguiar. Considerações sobre a interdisciplinaridade. In: PHILIPPI JUNIOR, Arlindo; TUCCI, Carlos E. Morelli; HOGAN, Daniel Joseph; NAVEGANTES, Raul (Ed.). Interdisciplinaridade em ciências ambientais. São Paulo: Signus, 2000. p. 52-70.

COSTA, Waldinete Conceição do Socorro Oliveira da. O papel da difusão científica no processo da educação ambiental e no incremento da alfabetização científica: aspectos gerais de uma pesquisa. In: (Org.). Comunicação da ciência e educação ambiental: resultados do workshop internacional. Belém, PA: Museu Paraense Emílio Goeldi, 1998. p. 19-32.

DIAS, Genebaldo Freire. Educação Ambiental: princípios e práticas. 8. ed. São Paulo: Gaia, 2003.

Atividades interdisciplinares de Educação Ambiental: práticas inovadoras de educação ambiental. 2. ed. São Paulo: Gaia, 2006.

. Dinâmicas e instrumentação para educação ambiental. São Paulo: Gaia, 2010.

DUSI, Raul Luis de Melo. Estudo Sobre Programas de Gestão Ambiental no Brasil e a Questão da Sustentabilidade Ambiental. 2006. 194 f. Tese (Doutorado em Ecologia) - Instituto de Ciências Biológicas, Universidade de Brasília, Brasília, 2006.

ECHEVERRÍA, Agustina Rosa; RODRIGUES, Fabiana Melo; SILVA, Kleber Rezende. Educação ambiental em escolas particulares de Goiânia: do diagnóstico a proposições sobre formação de professores. Pesquisa em Educação Ambiental, v. 4, n. 1, p. 63-86, 2009.

GADOTTI, Moacir. Perspectivas atuais da educação. São Paulo Perspec. [online], São Paulo, v. 14, n. 2, p. 3-11, 2000.

IZUWA, Magali; AUGUSTO, Fátima Mayumi Mizuno; ROMBALDI, Zilda Lopes. A inserção do enfoque ambiental no ensino formal de Goiás. Brasília: Ibama, 1997. (Série Meio Ambiente, v. 11).

JORGE, Marco Aurélio Pereira. Sustentabilidade e desenvolvimento local: estudo de projeto na 
formação da ecovila Viver Simples em Itamonte-MG. 2008. 162 f. Dissertação (Mestrado em Gestão Empresarial) - Centro de Formação Acadêmica e Pesquisa, Escola Brasileira de Administração Pública e de Empresas, Rio de Janeiro, 2008.

LEFF, Enrique. Complexidade, Interdisciplinaridade e Saber Ambiental. In: PHILIPPI JUNIOR, Arlindo; TUCCI, Carlos E. Morelli; HOGAN, Daniel Joseph; NAVEGANTES, Raul (Ed.). Interdisciplinaridade em ciências ambientais. São Paulo: Signus, 2000. p. 19-51.

MARTINS, Leila Chalub. Educação Ambiental e subjetividade: o papel de quem aprende no ato de aprender. Texto fotocopiado, 2005.

MEDINA, Naná Mininni. Elementos para a introdução da dimensão ambiental na educação escolar - $1^{\circ}$ grau. In: IBAMA. Amazônia: uma proposta interdisciplinar de educação ambiental: temas básicos. Brasília, 1994. p. 13-82. (Documentos Metodológicos).

MELO, Rosemeri Santos de. A dimensão ambiental da educação e as redes de informação e conhecimento. Revista Eletrônica do Mestrado em Educação Ambiental, Rio Grande, v. 5, p. 7-17, 2001.

MORIN, Edgar. Os sete saberes necessários à educação do futuro. 2. ed. São Paulo: Cortez, 2000.

NARCIZO, Kaliane Roberta dos Santos. Uma análise sobre a importância de trabalhar educação ambiental nas escolas. Revista Eletrônica do Mestrado em Educação Ambiental, Rio Grande, v. 22, p. 86-94, 2009.

NIETO CARAVEO, Luz María. Modalidades de la educación ambiental: diversidad y desafios. In: SANTOS, José Eduardo dos; SATO, Michèle (Org.). A contribuição da Educação Ambiental à esperança de Pandora. São Carlos: Rima, 2001. p. ix-xii. (Apresentação).

PESSOA, Gustavo Pereira; BRAGA, Rosalina Batista. Educação Ambiental escolar e qualidade de vida: desafios e possibilidades. Revista Eletrônica do Mestrado em Educação Ambiental, Rio Grande, v. 24, p. 142-155, 2010.

SANTOS, Aline Mendes Bernardes; TAGLIANI, Paulo Roberto Armanini; VIEIRA, Paulo Henrique Freire. Educação Ambiental em Garopaba: a visão dos professores e alunos do ensino fundamental local. Revista Eletrônica do Mestrado em Educação Ambiental, Rio Grande, v. 24, p. 219-232, 2010.

SATO, Michèle. Debatendo os desafios da educação ambiental. Revista Eletrônica do Mestrado em Educação Ambiental, Rio Grande, v. 1, p. 14-33, 2001.

SECRETARIA DE EDUCAÇÃO DO DISTRITO FEDERAL. Disponível em: <http://www.se.df.gov.br>. Acesso em: set. 2009. 
SINDICATO DOS ESTABELECIMENTOS PARTICULARES DE ENSINO. Disponível em: <http://www.sinepe-df.org>. Acesso em: set. 2009.

SOUZA, Karine Rísia Bomfim. Ações de educação ambiental em escolas públicas brasileiras. FÓRUM AMBIENTAL DA ALTA PAULISTA, 3., 2007, Tupã, SP.

TRAVASSOS, Edson Gomes. A Educação Ambiental nos currículos: dificuldades e desafios. Revista de Biologia e Ciências da Terra, v. 1, n. 2, 2001.

VARGAS, Liliana Angel. Educação ambiental: a base para uma ação político/transformadora na sociedade. Revista Eletrônica do Mestrado em Educação Ambiental, Rio Grande, v. 15, p. 72-79, 2005.

VEIGA, Alinne; AMORIM, Érica Pereira; BLANCO COSSÍO, Mauricio. Um retrato da presença da educaşão ambiental no ensino fundamental brasileiro: o percurso de um processo acelerado de expansão. Brasília: INEP, 2005.

Artigo recebido em 04/04/2011

Artigo aprovado em 05/09/2011 